\title{
Endoscopic treatment for Bouveret syndrome
}

\author{
Jin-cheng Zhao Ermilo Barrera $\cdot$ Mohammad Salabat \\ Woody Denham $\cdot$ Dennis Leung $\cdot$ Michael Ujiki
}

Received: 22 February 2012/ Accepted: 30 July 2012/Published online: 10 October 2012

(C) Springer Science+Business Media, LLC 2012

\begin{abstract}
Background Gallstone ileus is an uncommon cause for small bowel obstruction. Less than $3 \%$ of cases are due to a gallstone impacted in the duodenum or pylorus resulting in a gastric outlet obstruction, described by Bouveret in 1896 [4]. Most of the successful therapeutic maneuvers described involve open surgical removal of the stone through either a gastrotomy or duodenotomy, and reported morbidity is not insignificant [1-3, 5-7]. Endoscopic techniques continue to evolve, allowing for more complex procedures and avoidance of open surgery and its accompanying high morbidity. This video displays a rarely used endoscopic method of relieving gastric outlet obstruction caused by a stone in a patient with Bouveret syndrome.

Methods Video of successful endoscopic retrieval of a gallstone lodged in the pylorus is presented. An endoscopic retrieval basket is used, and key maneuvers highlighted include passage of the closed device distal to the stone, opening of the basket, and withdrawal of the stone under direct vision.

Results After successful retrieval, endoscopic inspection revealed a normal duodenum and relief of the obstruction. Cholecystectomy was not performed, given that most cholecystoduodenal fistulae are large and will spontaneously close,
\end{abstract}

Presented at the SAGES 2012 Annual Meeting, March 7-10, 2012, San Diego, CA.

Electronic supplementary material The online version of this article (doi:10.1007/s00464-012-2533-8) contains supplementary material, which is available to authorized users.

J. Zhao $\cdot$ E. Barrera $\cdot$ M. Salabat $\cdot$ W. Denham .

D. Leung $\cdot$ M. Ujiki $(\bowtie)$

Department of Surgery, NorthShore University HealthSystem,

Evanston, IL 60201, USA

e-mail: mujiki@northshore.org especially if a patent cystic duct is present. Liver function tests were normal postoperatively, so no further evaluation of the bile duct was necessary.

Conclusions With new advances in technology, the endoscopic approach should be considered as the first line of treatment for cases of Bouveret syndrome because most patients are elderly with multiple comorbidities.

Keyword Gallstone ileus · Endoscopy · Bouveret syndrome

Disclosures Drs. Jin-cheng Zhao, Ermilo Barrera, Mohammad Salabat, Woody Denham, Dennis Leung, and Michael Ujiki have no conflicts of interest or financial ties to disclose.

\section{References}

1. Ariche A, Czeiger D, Gortzak Y, Shaked G, Shelef I, Levy I (2000) Gastric outlet obstruction by gallstone: Bouveret syndrome. Scand J Gastroenterol 35:781-783

2. Reisner RM, Cohen JR (1994) Gallstone ileus: a review of 1001 reported cases. Am Surg 60:441-446

3. Sakarya A, Erhan MY, Aydede H, Kara E, Ozkol M, Ilkgül O, Ozsoy Y (2006) Gallstone ileus presenting as gastric outlet obstruction (Bouveret's syndrome): a case report. Acta Chir Belg 106(4):438-440

4. Bouveret L (1896) Stenose du pylore adhérent à la vesicule. Rev Med (Paris) 16:1-16

5. Erlandson MD, Kim AW, Richter HM III, Myers J (2009) Roux-en-Y duodenojejunostomy in the treatment of Bouveret syndrome. South Med J 2(9):963-965

6. O’Neill C, Colquhoun P, Schlachta CM, Etemad-Rezai R, Jayaraman S (2009) Gastric outlet obstruction secondary to biliary calculi: 2 cases of Bouveret syndrome. Can J Surg 52(1):E16-E18

7. Lowe AS, Stephenson S, Kay CL, May J (2005) Duodenal obstruction by gallstones (Bouveret's syndrome): a review of the literature. Endoscopy 37(1):82-87 